\title{
Commonly Used Acronyms
}

$\begin{array}{ll}\text { ACLU } & \text { American Civil Liberties Union } \\ \text { ACOG } & \text { American College of Obstetricians and Gynecologists } \\ \text { AIM } & \text { American Indian Movement } \\ \text { AMA } & \text { American Medical Association } \\ \text { BIA } & \text { Bureau of Indian Affairs } \\ \text { CDC } & \text { Centers for Disease Control } \\ \text { CHRs } & \text { community health representatives } \\ \text { CHS } & \text { contract health services } \\ \text { EBM } & \text { evidence-based medicine } \\ \text { EC } & \text { emergency contraception } \\ \text { GAO } & \text { US Government Accountability Office } \\ \text { HHS } & \text { US Department of Health and Human Services } \\ \text { IE } & \text { institutional ethnography } \\ \text { IHCIA } & \text { Indian Health Care Improvement Act } \\ \text { IHS } & \text { Indian Health Service } \\ \text { MCH } & \text { Maternal and Child Health } \\ \text { NAWHERC } & \text { Native American Women's Health } \\ & \text { Education Resource Center } \\ \text { TLOA } & \text { Tribal Law and Order Act } \\ \text { USPHS } & \text { US Public Health Service } \\ \text { VAWA } & \text { Violence Against Women Act } \\ \text { WARN } & \text { Women of All Red Nations }\end{array}$


